\title{
The complete chloroplast genome of Saxifraga sinomontana (Saxifragaceae) and comparative analysis with other Saxifragaceae species
}

\author{
Yan $\mathrm{Li}^{1,2} \cdot$ Liukun Jia $^{1,2} \cdot$ Zhihua Wang $^{1,2} \cdot$ Rui Xing $^{1} \cdot$ Xiaofeng Chi $^{1} \cdot$ Shilong Chen ${ }^{1} \cdot$ Qingbo Gao ${ }^{1,3}$
}

Received: 10 July 2019 / Revised: 24 September 2019 / Accepted: 26 September 2019 / Published online: 25 October 2019

(C) The Author(s) 2019

\begin{abstract}
Saxifraga sinomontana J.-T. Pan \& Gornall belongs to Saxifraga sect. Ciliatae subsect. Hirculoideae, a lineage containing ca. 110 species whose phylogenetic relationships are largely unresolved due to recent rapid radiations. Analyses of complete chloroplast genomes have the potential to significantly improve the resolution of phylogenetic relationships in this young plant lineage. The complete chloroplast genome of $S$. sinomontana was de novo sequenced, assembled and then compared with that of other six Saxifragaceae species. The $S$. sinomontana chloroplast genome is $147,240 \mathrm{bp}$ in length with a typical quadripartite structure, including a large single-copy region of 79,310 bp and a small single-copy region of 16,874 bp separated by a pair of inverted repeats (IRs) of $25,528 \mathrm{bp}$ each. The chloroplast genome contains 113 unique genes, including 79 protein-coding genes, four rRNAs and 30 tRNAs, with 18 duplicates in the IRs. The gene content and organization are similar to other Saxifragaceae chloroplast genomes. Sixty-one simple sequence repeats were identified in the S. sinomontana chloroplast genome, mostly represented by mononucleotide repeats of polyadenine or polythymine. Comparative analysis revealed 12 highly divergent regions in the intergenic spacers, as well as coding genes of $m a t K, n d h K, \operatorname{accD}, \operatorname{cemA}, \operatorname{rpoA}$, rps 19, ndhF, ccsA, ndhD and $y c f 1$. Phylogenetic reconstruction of seven Saxifragaceae species based on 66 protein-coding genes received high bootstrap support values for nearly all identified nodes, suggesting a promising opportunity to resolve infrasectional relationships of the most species-rich section Ciliatae of Saxifraga.
\end{abstract}

Keywords Comparative genomics · Genome assembly $\cdot$ Phylogenetic analysis $\cdot$ Saxifraga sect. Ciliatae

\section{Introduction}

Electronic supplementary material The online version of this article (https://doi.org/10.1007/s40415-019-00561-y) contains supplementary material, which is available to authorized users.

\section{Qingbo Gao}

qbgao@nwipb.cas.cn

Yan Li

liyan715@mails.ucas.ac.cn

Liukun Jia

jialiukun@qq.com

Zhihua Wang

304339275@qq.com

Rui Xing

xingrui@nwipb.cas.cn

Xiaofeng Chi

xfchi@nwipb.cas.cn
Saxifraga L. is the largest genus of Saxifragaceae, consisting of 450-500 species in at least 13 sections (Tkach et al. 2015; Ebersbach et al. 2017a; Gao et al. 2017; Li et al. 2018). The most species-rich section of Saxifraga is

Shilong Chen

slchen@nwipb.cas.cn

1 Key Laboratory of Adaptation and Evolution of Plateau Biota, Northwest Institute of Plateau Biology, Chinese Academy of Sciences, Xining 810001, China

2 University of Chinese Academy of Sciences, Beijing 100039, China

3 Qinghai Provincial Key Laboratory of Crop Molecular Breeding, Xining 810001, China 
Saxifraga sect. Ciliatae Haw. (ca. 175 species) (Pan et al. 2001), whose diversity center is the Qinghai-Tibetan Plateau (QTP) and Himalayas (Gao et al. 2015; Ebersbach et al. 2018). In addition, Saxifraga sect. Ciliatae is supposed to have experienced recent rapid radiations in the QTP region, particularly in Saxifraga sect. Ciliatae subsect. Hirculoideae Engl. \& Irmsch. (Gao et al. 2015; Ebersbach et al. 2017b, 2018). Rapid radiations are usually associated with low genetic divergence among closely related species and clades (DeChaine et al. 2013), and thus, phylogenetic relationships could not be well resolved based on a limited number of DNA markers. This is also the case in Saxifraga sect. Ciliatae. Concerning to Saxifraga sect. Ciliatae subsect. Hirculoideae, relationships of its ca. 110 species are largely unresolved based on traditionally universal DNA markers (Gao et al. 2015). Furthermore, enigmatic species from Saxifraga sect. Ciliatae subsect. Hirculoideae could not be identified based on universal barcodes. New genomic resources are urgent to assist phylogenetic reconstruction and taxonomic classification of Saxifraga sect. Ciliatae. Here, we report the complete chloroplast genomes of seven species in Saxifraga sect. Ciliatae.

Analyses of complete chloroplast genomes have the advantage to significantly improve the resolution of phylogenetic relationships in large, complex plant lineages (Jansen et al. 2007; Doorduin et al. 2011), even in enigmatic taxa (Dong et al. 2018). Chloroplast genomes are closed circular DNA molecules in most angiosperms, which have a conserved quadripartite structure consisting of a large singlecopy (LSC) region and a small single-copy (SSC) region interspersed between a pair of inverted repeats (IR) (Palmer 1985; Wicke et al. 2011). The chloroplast genome size of angiosperms ranges from 120 to $160 \mathrm{~kb}$, encoding 110-130 genes (Palmer 1985). Due to the characteristics of uniparental inheritance, haploid nature, conserved structure and gene content, small genome size, chloroplast genomes have been widely applied in phylogenetic reconstructions (Burke et al. 2016; Simmons 2017; Dong et al. 2018), molecular evolution (Huang et al. 2014; Walker et al. 2014) and superbarcoding studies (Hernández-León et al. 2013). With the recent advent of next-generation sequencing (NGS) techniques, the complete chloroplast genome sequences have grown rapidly. However, up to now, only one chloroplast genome of Saxifraga has been reported, Saxifraga stolonifera Curtis (GenBank accession no. NC_037882), a member of $S$. sect. Irregulares Haw. No chloroplast genome has been reported for the mostspecies-rich sect. Ciliatae of Saxifraga.

Saxifraga sinomontana J.-T. Pan \& Gornall, belonging to $S$. sect. Ciliatae subsect. Hirculoideae is a prominent element of the high-altitude habitats throughout the QTP-Himalayas region. This perennial herb is extraordinarily variable in morphology and shows high level of intraspecific genetic diversity, which was considered to have experienced recent rapid intraspecific differentiation associated with Quaternary climatic oscillations ( $\mathrm{Li}$ et al. 2018). Here, we de novo sequenced and assembled the complete chloroplast genome of $S$. sinomontana using an Illumina sequencing platform. Comparative analysis between this newly sequenced chloroplast genome and other six reported Saxifragaceae chloroplast genomes was implemented, and the putative performance for phylogenetic study on Saxifraga and Saxifragaceae was assessed.

\section{Materials and methods}

Sample collection, genome sequencing and assembly Fresh leaves of Saxifraga sinomontana were sampled in Xuebudala pass, Longzi xian, Xizang Autonomous Region, China $\left(28^{\circ} 37^{\prime} 58.6^{\prime \prime} \mathrm{N}, 92^{\circ} 13^{\prime} 09.2^{\prime \prime} \mathrm{E}\right)$. Leaves were collected from a single individual, then dried in silica gel. Voucher specimen was deposited in the herbarium of Northwest Institute of Plateau Biology (HNWP), Xining, Qinghai, China.

Total genomic DNA was isolated from silica-dried leaves using the modified CTAB method (Doyle and Doyle 1987). Genomic library was then prepared using the TruSeq Library Construction Kit (Illumina, San Diego, California, USA) following the manufacturer's instructions. Briefly, ca. $5 \mu \mathrm{g}$ of genomic DNA was fragmented via ultrasound, followed by purification using CASpure PCR Purification Kit (ChaoshiBio, Shanghai, China) and end repair with poly-A on the 3' ends. The DNA fragments were then linked to adapters, extracted at specific size after agarose gel electrophoresis and amplified by PCR to generate a sequencing library. Genomic and chroloplast DNA were sequenced using the Illumina NovaSeq platform (Novogene, Tianjin, China), yielding ca. $5 \mathrm{~Gb} 150$-bp paired-end reads from a library of approximately 350-bp DNA fragments.

The BWA-MEM algorithm was performed to map chloroplast DNA reads against the complete chloroplast genome sequence of S. stolonifera (NC_037882) as implemented in BWA 0.7.17 (Li and Durbin 2009). A total of 7,204,234 paired-end reads were recovered and then assembled using SPAdes 3.13.0 (Bankevich et al. 2012). Six contigs, ranging in size from 2993 to $60,980 \mathrm{bp}$, were obtained, followed by a further scaffolding using SSPACE-basic 2.0 (Boetzer et al. 2011). The gaps between the de novo contigs, as well as genomic regions located at the junction between the two contigs were filled and verified by Sanger sequencing. The primers used were designed using Primer-BLAST (Ye et al. 2012) and are listed in Supplementary Table S1.

Genome annotation and simple sequence repeats analysis The genome was annotated using the program GeSeq (Tillich et al. 2017). The predicted annotations were verified 
using BLAST search against cp genomes of other closely related species to validate positions of questionable start and stop codons. The circular cp genome map was drawn using OGDRAW (Greiner et al. 2019). The complete chloroplast genome of $S$. sinomontana was deposited into GenBank, with the accession of MN104589.

Simple sequence repeats (SSRs) were detected using MISA (Thiel et al. 2003) with minimal repeat numbers of $10,5,4,3,3$ and 3 for mono-, di-, tri-, tetra-, penta- and hexa-nucleotides, respectively.

Comparison with other Saxifragaceae chloroplast genomes - Sequence length of complete chloroplast genomes, as well as each individual regions were compared among $S$. sinomontana and six other Saxifragaceae species, S. stolonifera (NC_037882), Bergenia scopulosa T. P. Wang (NC_036061), Chrysosplenium aureobracteatum Y. I. Kim \& Y. D. Kim (NC_039740), Heuchera parviflora Bartling var. saurensis R. A. Folk (KR478645), Mukdenia rossii (Oliv.) Koidz. (NC_037495), Oresitrophe rupifraga Bunge (NC_037514). The percentage of GC-content was calculated using MEGA version 7.0.26 (Kumar et al. 2016). The percentage of sequence identity among complete chloroplast genomes of the seven Saxifragaceae species was comparatively analyzed and plotted using the program mVISTA (Frazer et al. 2004), with alignment algorithm of LAGAN (Brudno et al. 2003), a cut-off of $70 \%$ identity and annotation of $S$. sinomontana as reference. Comparison of junction sites of LSC, IR and SSC regions among these Saxifragaceae chloroplast genomes was implemented using the program IRscope (Amiryousefi et al. 2018).

Phylogenetic analysis - To estimate the putative performance of chloroplast genomes on phylogeny resolution of Saxifragaceae species, phylogenetic relationships of the above-mentioned species were inferred, using Ribes fasciculatum Siebold \& Zucc. var. chinense Maxim. (MH191388) and Itea chinensis Hook. \& Arn. (NC_037884) as outgroups. A set of 66 protein-coding genes ( $p s a A, p s a B, p s a C$, psaI, $p s a J, p s b A, p s b C, p s b D, p s b E, p s b F, p s b H, p s b J, p s b K$, psbL, psbM, psbN, psbT, psbZ, petA, petB, petD, pet $G, \operatorname{pet} L$, pet $N$, atpA, atpB, atpE, atpF, atpH, atpI, rbcL, ndhA, ndhB, $n d h C, n d h D, n d h E, n d h F, n d h G, n d h H, n d h I, n d h J, n d h K$, rpl2, rpl14, rpl16, rpl20, rpl22, rpl23, rpl32, rpl33, rpl36, rps2, rps3, rps4, rps7, rps8, rps11, rps14, rps15, rps16, rps 18, rps 19, rрoA, rрoB, rpoC1 and rpoC2) shared by all of the species were extracted from all the selected chloroplast genomes. Individual PCGs were concatenated into a single matrix and then aligned using MEGA version 7.0.26 (Kumar et al. 2016). Phylogenetic analysis was performed by mean of Maximum Likelihood (ML) using RAxML version 8.1.21 (Stamatakis 2014) implemented in raxmlGUI version $1.5 \mathrm{~b} 2$
(Silvestros and Michalak 2012). The best-fit substitution model of GTR $+\mathrm{I}+\mathrm{G}$ was selected by the Akaike Information Criteria (AIC) using jModelTest version 2.1.4 (Darriba et al. 2012). Bootstrap support assessment was performed with 1000 replications.

\section{Results}

Genome content and structure of S. sinomontana - The chloroplast genome of $S$. sinomontana is a closed circular molecule of $147,240 \mathrm{bp}$ with a typical quadripartite structure, including the LSC of 79,310 bp and SSC of 16,874 bp separated by a pair of IRs of 25,528 bp each (Fig. 1; Table 3). The GC-contents of the LSC, SSC, IR regions and the overall chloroplast genome of $S$. sinomontana are $36.2 \%, 32.0 \%$, $42.9 \%$ and $38.0 \%$, respectively (Table 3 ). The comparative analysis revealed that the chloroplast genome size of $S$. sinomontana is the smallest among all the seven Saxifragaceae chloroplast genomes, with 3826 bp shorter than its congeneric species, S. stolonifera (Table 3). Although the sizes of the overall genome, LSC, SSC and IR regions are different to some extent, the GC-contents of the complete chloroplast genomes and of each individual regions are similar among the seven Saxifragaceae species (Table 3).

The chloroplast genome of $S$. sinomontana contains 79 unique protein-coding genes, seven of which are duplicated ( $n d h B, r p l 2, r p l 23, r p s 7$ and $y c f 2$ ) or partially duplicated (rps19, ycfl) in the IR. Four rRNA genes were identified in this genome, all of which are completely duplicated in the IR regions. In addition, 30 unique tRNA genes were annotated, among which, seven are duplicated. In total, the $S$. sinomontana chloroplast genome contains 131 genes (Table 1). Among them, 17 genes contain introns, including 11 proteincoding genes and six tRNA genes, almost all of which are single-intron genes except for $y c f 3$ and $c l p P$. Like most other angiosperms (Nie et al. 2012; Hu et al. 2015; Wang et al. 2017; Yan et al. 2019), the rps 12 gene is trans-spliced, with its 5'-end exon located in the LSC region and 3'-end exon duplicated in the IRs. In general, both the content and order of genes present in S. sinomontana chloroplast genome are similar to those present in other Saxifragaceae species.

Simple sequence repeats analysis - Sixty-one SSRs, ranging from 10 to $17 \mathrm{bp}$ in length, were detected in the $S$. sinomontana chloroplast genome (Table 2). The total length of the 61 SSRs found in $S$. sinomontana is $713 \mathrm{bp}$ with an AT content of $95.1 \%$, much higher than the rest of the genome. The mononucleotide repeat is the most abundant SSR type (41 out of 61) in $S$. sinomontana chloroplast genome, representing $67.2 \%$ of the total SSR loci. Among the 41 mononucleotide repeats, 40 are $\mathrm{A}$ or $\mathrm{T}$ types, whereas the number 


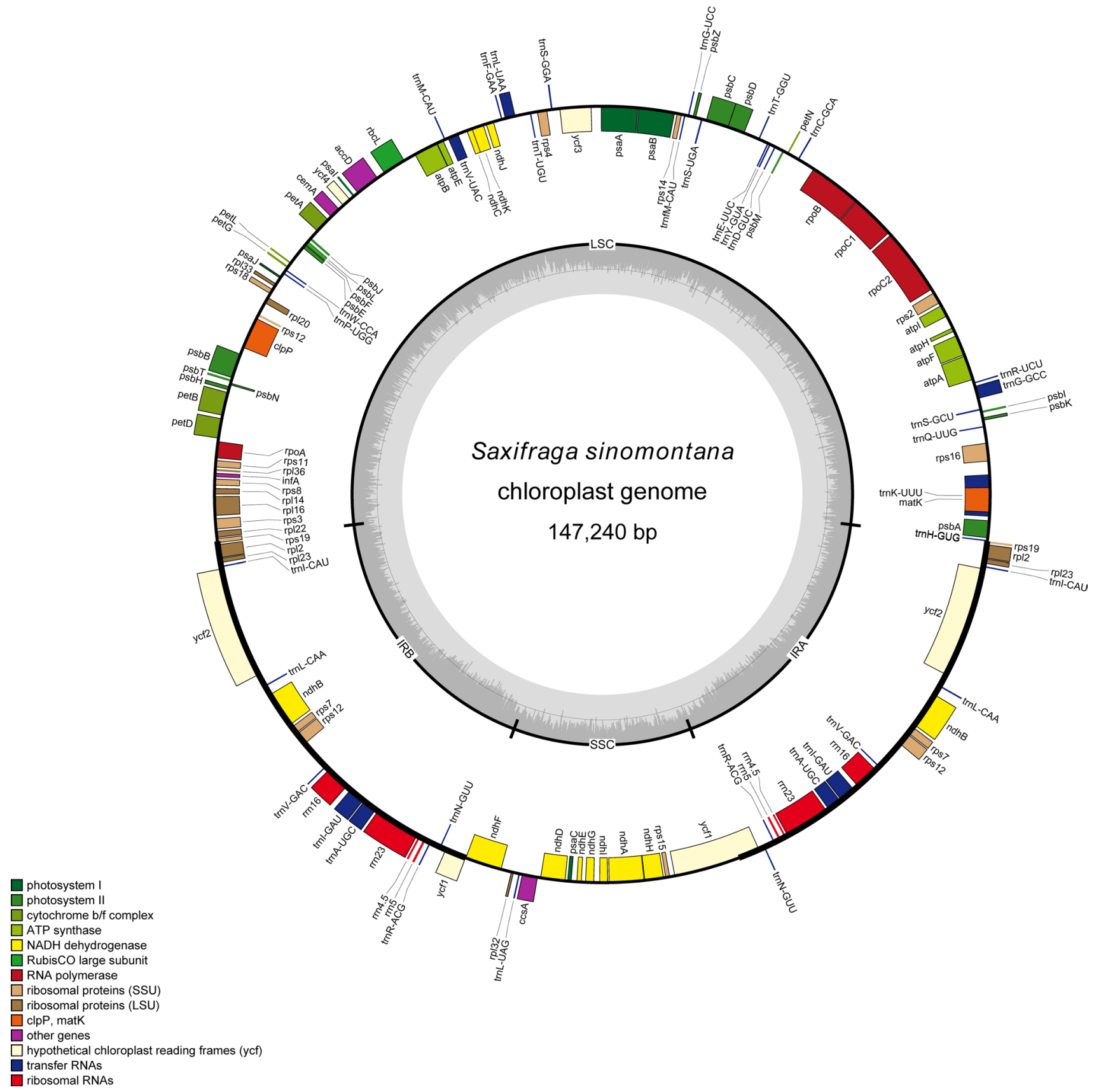

Fig. 1 Chloroplast genome map of Saxifraga sinomontana. Genes drawn inside of the outer circle are transcribed clockwise, and those outside are transcribed counterclockwise. Genes belonging to different functional groups are shown in different colors. The innermost darker gray corresponds to GC-content while the lighter gray corresponds to AT content

of di-, tri-, tetra-, and penta-nucleotide repeats detected in $S$. sinomontana chloroplast genome are 10 , five, four and one, respectively. No hexanucleotide repeats were detected in this chloroplast genome. Among the 61 SSRs, 35 are located in the intergenic regions, 11 in introns, and 15 in protein-coding genes, including $y c f 1, r p o B, a t p B, n d h F, r p o C 1, r p s 14$, psbC, rpoC2, rpl22 genes (Table 2).
Chloroplast genome comparisons - The overall sequence identity of seven chloroplast genomes of Saxifragaceae species was plotted using mVISTA with the annotation of $S$. sinomontana chloroplast genome as reference (Fig. 2). The results showed that the Saxifragaceae chloroplast genomes exhibited a high level of sequence synteny, suggesting a conserved evolutionary pattern. In addition, the IR regions are less divergent compared to the LSC and SSC regions. 
Table 1 Genes present in Saxifraga sinomontana chloroplast genome

\begin{tabular}{|c|c|c|}
\hline No. & Gene types & Gene products \\
\hline 1 & Photosystem I & psaA, B, C, I, J, ycf3 ${ }^{\mathrm{a}}$ \\
\hline 2 & Photosystem II & psbA, B, C, D, E, F, H, I, J, K, L, M, N, T, Z \\
\hline 3 & Cytochrome b6/f & petA, $\mathrm{B}^{\mathrm{b}}, \mathrm{D}^{\mathrm{b}}, \mathrm{G}, \mathrm{L}, \mathrm{N}$ \\
\hline 4 & Atp synthase & $\operatorname{atpA}, \mathrm{B}, \mathrm{E}, \mathrm{F}^{\mathrm{b}}, \mathrm{H}, \mathrm{I}$ \\
\hline 5 & Rubisco & $\mathrm{rbcL}$ \\
\hline 6 & NADH oxidoreductase & $n d h A^{b}, B^{b, c}, C, D, E, F, G, H, I, J, K$ \\
\hline 7 & Large subunit ribosomal proteins & $\mathrm{rp} 12^{\mathrm{c}}, 14,16^{\mathrm{b}}, 20,22,23^{\mathrm{c}}, 32,33,36$ \\
\hline 8 & Small subunit ribosomal proteins & $\operatorname{rps} 2,3,4,7^{\mathrm{c}}, 8,11,12^{\mathrm{b}, \mathrm{c}, \mathrm{d}}, 14,15,16^{\mathrm{b}}, 18,19^{\mathrm{c}}$ \\
\hline 9 & RNAP & $\operatorname{rpoA}, \mathrm{B}, \mathrm{C} 1^{\mathrm{b}}, \mathrm{C} 2$ \\
\hline 10 & Other proteins & $\operatorname{accD}, \operatorname{ccs} A, \operatorname{cem} A, \operatorname{clpP} P^{a}, \inf A$, matK \\
\hline 11 & Proteins of unknown function & $\mathrm{ycf} 1^{\mathrm{c}}, \mathrm{ycf} 2^{\mathrm{c}}, \mathrm{ycf} 4$ \\
\hline 12 & Ribosomal RNAs & $\operatorname{rrn} 4.5^{\mathrm{c}}, 5^{\mathrm{c}}, 16^{\mathrm{c}}, 23^{\mathrm{c}}$ \\
\hline 13 & Transfer RNAs & $\begin{array}{l}\operatorname{trnA}(\mathrm{UGC})^{\mathrm{b}, \mathrm{c}}, \mathrm{C}(\mathrm{GCA}), \mathrm{D}(\mathrm{GUC}), \mathrm{E}(\mathrm{UUC}), \mathrm{F}(\mathrm{GAA}), \mathrm{fM}(\mathrm{CAU}), \\
\text { G(GCC) })^{\mathrm{b}}, \mathrm{G}(\mathrm{UCC}), \mathrm{H}(\mathrm{GUG}), \mathrm{I}(\mathrm{CAU})^{\mathrm{c}}, \mathrm{I}(\mathrm{GAU})^{\mathrm{b}, \mathrm{c}}, \mathrm{K}(\mathrm{UUU})^{\mathrm{b}}, \\
\text { L(CAA) })^{\mathrm{c}}, \mathrm{L}(\mathrm{UAA})^{\mathrm{b}}, \mathrm{L}(\mathrm{UAG}), \mathrm{M}(\mathrm{CAU}), \mathrm{N}(\mathrm{GUU})^{\mathrm{c}}, \mathrm{P}(\mathrm{UGG}), \\
\text { Q(UUG), R(ACG) })^{\mathrm{c}}, \mathrm{R}(\mathrm{UCU}), \mathrm{S}(\mathrm{GCU}), \mathrm{S}(\mathrm{GGA}), \mathrm{S}(\mathrm{UGA}), \mathrm{T}(\mathrm{GGU}), \\
\text { T(UGU), V(GAC) })^{\mathrm{c}}, \mathrm{V}(\mathrm{UAC})^{\mathrm{b}}, \mathrm{W}(\mathrm{CCA}), \mathrm{Y}(\mathrm{GUA})\end{array}$ \\
\hline
\end{tabular}

${ }^{\mathrm{a}}$ Gene containing two introns

${ }^{\mathrm{b}}$ Gene containing a single intron

${ }^{\mathrm{c}}$ Two gene copies in IRs

${ }^{\mathrm{d}}$ Gene divided into two independent transcription units

The most divergent coding regions in the seven chloroplast genomes are matK, ndhK, accD, cemA, rpoA, rps19, ndhF, $\operatorname{ccs} A, n d h D, y c f l$. The most divergent regions among the seven chloroplast genomes are located in the intergenic spacers, including trnK-UUU-rps16, rps16-trnQ-UUG, trnSGCU-trnG-GCC, atpH-atpI, trnE-UUC-trnT-GGU, trnT$U G U$-trnL-UAA, ndhC-trnV-UAC, petA-petJ, psbE-petL, $n d h F-r p l 32$, rpl32-trnL-UAG, trnH-GUG-psbA (Fig. 2).

In this study, the LSC/IRB/SSC/IRA boundaries and the adjacent genes were compared across the seven Saxifragaceae chloroplast genomes (Fig. 3). The B. scopulosa chloroplast genome showed dramatic variation in boundaries of IRB/SSC and SSC/IRA compared to the other chloroplast genomes, with its $n d h F$ and duplicated $y c f l$ genes completely located in the SSC region, resulting in the largest SSC of 21,920 bp but smallest IR of 23,811 bp among the seven Saxifragaceae chloroplast genomes (Table 3; Fig. 3). For the remaining six chloroplast genomes, expansion/ contraction of IRs were also detected: the LSC/IRB border located within the coding region of $r p s 19$ or $r p l 22$, or within the intergenic spacer between $r p s 19$ and $r p l 2$; the IRB/SSC junction fell into the $y c f l$ pseudogene and/or $n d h F$ gene; the SSC/IRA border located within the $y c f l$ gene, but with different extensions (Fig. 3). However, the IRA/LSC junction showed a complex pattern among the remaining six chloroplast genomes: (1) within the coding region of $t r n H-G U G$ (S. sinomontana); (2) within the intergenic spacer between partially or completely duplicated rps 19 gene and $t r n H$ GUG (S. stolonifera and H. parviflora var. saurensis); (3) within the intergenic spacer of rpl2-trnH-GUG without a duplication of rps19 between them (C. aureobracteatum, $M$. rossii and $O$. rupifraga).

Phylogenetic analysis - Aset of 66 protein-coding genes sharing among the seven Saxifragaceae chloroplast genomes were extracted, and phylogenetic relationships were reconstructed with $R$. fasciculatum var. chinense and I. chinensis as outgroups. The ML tree topology was consistent with previous studies, which confirmed Saxifraga sensu stricto as a monophyletic clade (Deng et al. 2015; Tkach et al. 2015). The ML bootstrap values based on the 66 shared genes were fairly high, and all but one node presented a bootstrap value of $100 \%$ (Fig. 4).

\section{Discussion}

The genome structure of $S$. sinomontana is consistent with that of most terrestrial plants (Palmer 1985), and the size $(147,240 \mathrm{bp})$ falls well into the range of $120-160 \mathrm{~kb}$ of angiosperm chloroplast genomes (Palmer 1985). In general, gene content and genome organization of angiosperm chloroplast genomes are highly conserved compared to nuclear and mitochondrial genomes (Wicke et al. 2011). However, extensive gene losses and large inversions have 
Table 2 Simple sequence repeat in Saxifraga sinomontana chloroplast genome

\begin{tabular}{|c|c|c|c|c|}
\hline Unit & Length & SSR start & SSR end & location \\
\hline \multirow[t]{18}{*}{ A } & \multirow[t]{7}{*}{10} & 8313 & 8322 & $\operatorname{trnS}-G C U-\operatorname{trnG}-\mathrm{GCC}$ \\
\hline & & 8779 & 8788 & trnG-GCC intron \\
\hline & & 27,015 & 27,024 & rpoB-trnC-GCA \\
\hline & & 51,951 & 51,960 & atpB-rbcL \\
\hline & & 63,854 & 63,863 & rps18-rpl20 \\
\hline & & 71,934 & 71,943 & petD intron \\
\hline & & 111,072 & 111,081 & ndhD-psaC \\
\hline & \multirow[t]{3}{*}{11} & 4554 & 4564 & matK-rps 16 \\
\hline & & 34,228 & 34,238 & psbZ-trnG-UCC \\
\hline & & 76,514 & 76,524 & rpl14-rpl16 \\
\hline & \multirow[t]{4}{*}{12} & 11,421 & 11,432 & atpA-atpF \\
\hline & & 15,696 & 15,707 & rps2-rpoC2 \\
\hline & & 44,897 & 44,908 & $\operatorname{trnT}$-UGU-trnL-UAA \\
\hline & & 66,120 & 66,131 & clpP intron \\
\hline & 14 & 118,540 & 118,553 & ycf1 \\
\hline & 15 & 65,709 & 65,723 & clpP intron \\
\hline & 16 & 45,296 & 45,311 & trnL-UAA intron \\
\hline & 17 & 7765 & 7781 & psbK-psbI \\
\hline \multirow[t]{22}{*}{$\mathrm{T}$} & \multirow[t]{6}{*}{10} & 25,508 & 25,517 & rpoB \\
\hline & & 51,424 & 51,433 & atpB \\
\hline & & 61,581 & 61,590 & petL-petG \\
\hline & & 73,215 & 73,224 & petD-rpoA \\
\hline & & 105,469 & 105,478 & ndhF \\
\hline & & 105,623 & 105,632 & ndhF \\
\hline & \multirow[t]{9}{*}{11} & 4281 & 4291 & matK-rps 16 \\
\hline & & 6231 & 6241 & rps16-trnQ-UUG \\
\hline & & 12,792 & 12,802 & atpF-atpH \\
\hline & & 20,271 & 20,281 & rpoC1 \\
\hline & & 27,141 & 27,151 & rpoB-trnC-GCA \\
\hline & & 35,030 & 35,040 & rps14 \\
\hline & & 75,476 & 75,486 & infA-rps8 \\
\hline & & 77,866 & 77,876 & rpl16-rps3 \\
\hline & & 119,525 & 119,535 & ycf1 \\
\hline & \multirow[t]{2}{*}{12} & 43,784 & 43,795 & rps4-trnT-UGU \\
\hline & & 120,694 & 120,705 & ycf1 \\
\hline & \multirow[t]{3}{*}{13} & 15,667 & 15,679 & rps2-rpoC2 \\
\hline & & 40,151 & 40,163 & psaA-ycf3 \\
\hline & & 62,708 & 62,720 & psaJ-rpl33 \\
\hline & 14 & 22,255 & 22,268 & rpoC1 intron \\
\hline & 15 & 119,813 & 119,827 & ycf1 \\
\hline G & 11 & 32,461 & 32,471 & $\mathrm{psbC}$ \\
\hline \multirow[t]{3}{*}{ AT } & 10 & 19,242 & 19,251 & rpoC2 \\
\hline & 12 & 30,503 & 30,514 & $\operatorname{trnT}$-GGU-psbD \\
\hline & 14 & 107,171 & 107,184 & ndhF-rpl32 \\
\hline
\end{tabular}

Table 2 (continued)

\begin{tabular}{llrrl}
\hline Unit & Length & SSR start & SSR end & location \\
\hline TA & 10 & 8246 & 8255 & trnS-GCU-trnG-GCC \\
& & 44,365 & 44,374 & trnT-UGU-trnL-UAA \\
& & 62,105 & 62,114 & trnW-CCA-trnP-UGG \\
& & 63,293 & 63,302 & rpl33-rps18 \\
& 12 & 105,611 & 105,622 & ndhF \\
& 14 & 64,542 & 64,555 & rpl20-rps12 \\
& 10 & 18,255 & 18,264 & rpoC2 \\
TC & 12 & 1488 & 1499 & psbA-trnK-UUU \\
ATA & 15 & 41,487 & 41,501 & ycf3 intron \\
& 12 & 45,252 & 45,263 & trnL-UAA intron \\
TAT & & 48,281 & 48,292 & ndhC-trnV-UAC \\
& 12 & 76,082 & 76,093 & rps8-rpl14 \\
ATG & 12 & 41,127 & 41,138 & ycf3 intron \\
TTTC & 12 & 70,675 & 70,686 & petB intron \\
AAAT & 12 & 79,025 & 79,036 & rpl22 \\
ACAT & 12 & 115,030 & 115,041 & ndhA intron \\
CCAA & 12 & 26,190 & 26,204 & rpoB-trnC-GCA \\
TATTG & 15 & & & \\
\hline & & & &
\end{tabular}

been detected in several lineages, such as Gentianaceae (Fu et al. 2016; Sun et al. 2018), Asteraceae (Jansen and Palmer 1987; Liu et al. 2013; Walker et al. 2014), Leguminosae (Doyle et al. 1992, 1996). In the present study, no extensive gene losses and large inversions were detected among Saxifragaceae chloroplast genomes. In addition, comparing the complete chloroplast genome of $S$. sinomontana with that of other six Saxifragaceae species, we found that the size of $S$. sinomontana chloroplast genome is the smallest among the compared Saxifragaceae species, but the organization and gene content is highly similar.

Chloroplast SSRs usually exhibit high levels of variations and are widely used in polymorphism investigations, population genetics and phylogenetic analyses (Powell et al. 1995; Provan et al. 1999, 2001; Flannery et al. 2006; Xue et al. 2012; Li et al. 2019). For S. sinomontana, the number of cpSSRs (sixty-one) is moderate compared with other species of angiosperms (Liu et al. 2013; Fu et al. 2016; Yan et al. 2019). According to this and previous studies (Liu et al. 2013; Fu et al. 2016; Yan et al. 2019), extremely high AT contents of cpSSR sequences seem to be a common phenomenon in higher plant chloroplast genomes. In S. sinomontana, the mononucleotide repeat types are consistent with previous finding that short polyadenine or polythymine repeats are main contributors to SSRs in chloroplast genome (Kuang et al. 2011), and the distribution pattern of cpSSRs between coding and non-coding regions is consistent with most angiosperm species (Nie et al. 2012).

Although chloroplast genomes are considered to be rather conservative among angiosperm species, regions with high 


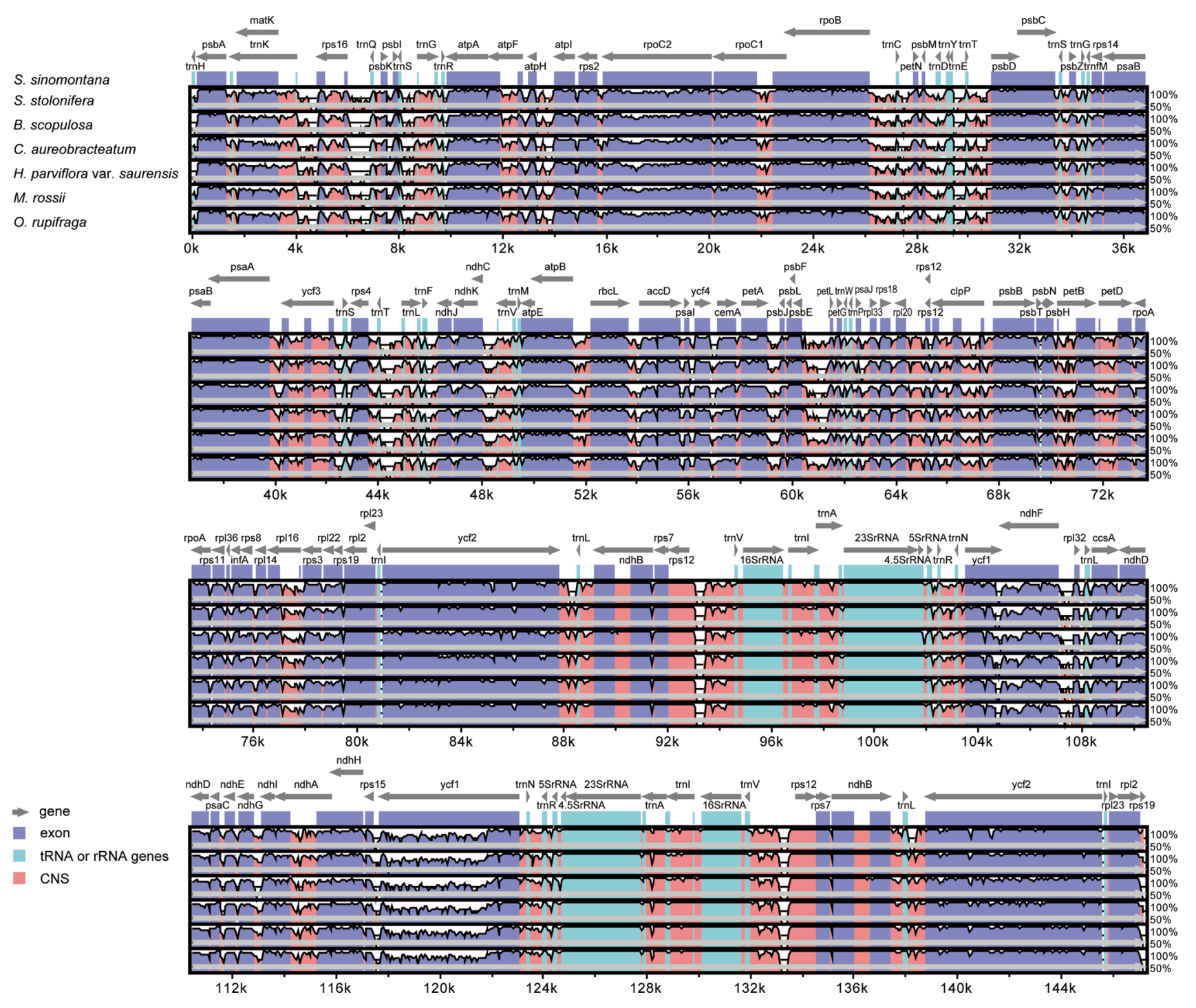

Fig. 2 Percentage of sequence identity between chloroplast genomes of Saxifraga sinomontana and other six Saxifragaceae species using mVISTA program. Gray arrows on the top line show transcriptional direction. The $y$-axis represents average percent identity between sequences of S. sinomontana and other six Saxifragaceae chloroplast genomes. The $x$-axis represents the coordinate in the chloroplast genome using $S$. sinomontana as reference. Genome regions are color coded as exon, tRNA, rRNA, and conserved non-coding sequences (CNS)

sequence polymorphisms are frequently observed even among closely related species (Kim and Jansen 1995). These highly divergent regions are widely used in plant phylogenetics, population genetics and DNA barcoding studies. Similar to other angiosperms (Nie et al. 2012; Liu et al. 2013; Chi et al. 2018; Yan et al. 2019), the coding regions of seven Saxifragaceae chloroplast genomes are more conservative than the non-coding regions. Among the ten most divergent coding regions in this study, mat $K$ has been considered as core universal DNA barcodes in many species ( $\mathrm{Li}$ et al. 2019), and $y c f l$ has recently been widely applied in plant phylogeny and DNA barcoding studies (Dong et al. 2015; Yang et al. 2017). Besides, accD, rps19, ccsA and $n d h F$ have also been proved to exhibit large divergence among various plant lineages and can be applied in phylogenetic studies (Ni et al. 2016; Ivanova et al. 2017). The boundaries of IRs and LSC/SSC differs among various plant species (Nie et al. 2012; Ni et al. 2016; Yan et al. 2019; Li et al. 2019), and expansion/extraction of the IR regions often lead to size variation of chloroplast genomes (Wang et al. 2008). Among the Saxifragaceae family, although various variations in the contraction/expansion of IRs have been detected, the IR sequences are not consistent with the total size of chloroplast genomes (Nie et al. 2012).

A number of phylogenetic studies have been conducted to clarify relationships within the family Saxifragaceae (Soltis et al. 2001, 2013; Xiang et al. 2012; DeChaine et al. 2013; Zhu et al. 2013; Deng et al. 2015), or within 
Fig. 3 Comparison of the junction sites of LSC, IR and SSC regions among seven Saxifragaceae chloroplast genomes. Selected genes are indicated by boxes along the genome. Genes above the genome lines indicate their transcriptions in forward direction, while below in reverse direction. $J L B$ junction between LSC and IRB, $J S B$ junction between SSC and IRB, $J S A$ junction between SSC and IRA, JLA junction between LSC and IRA

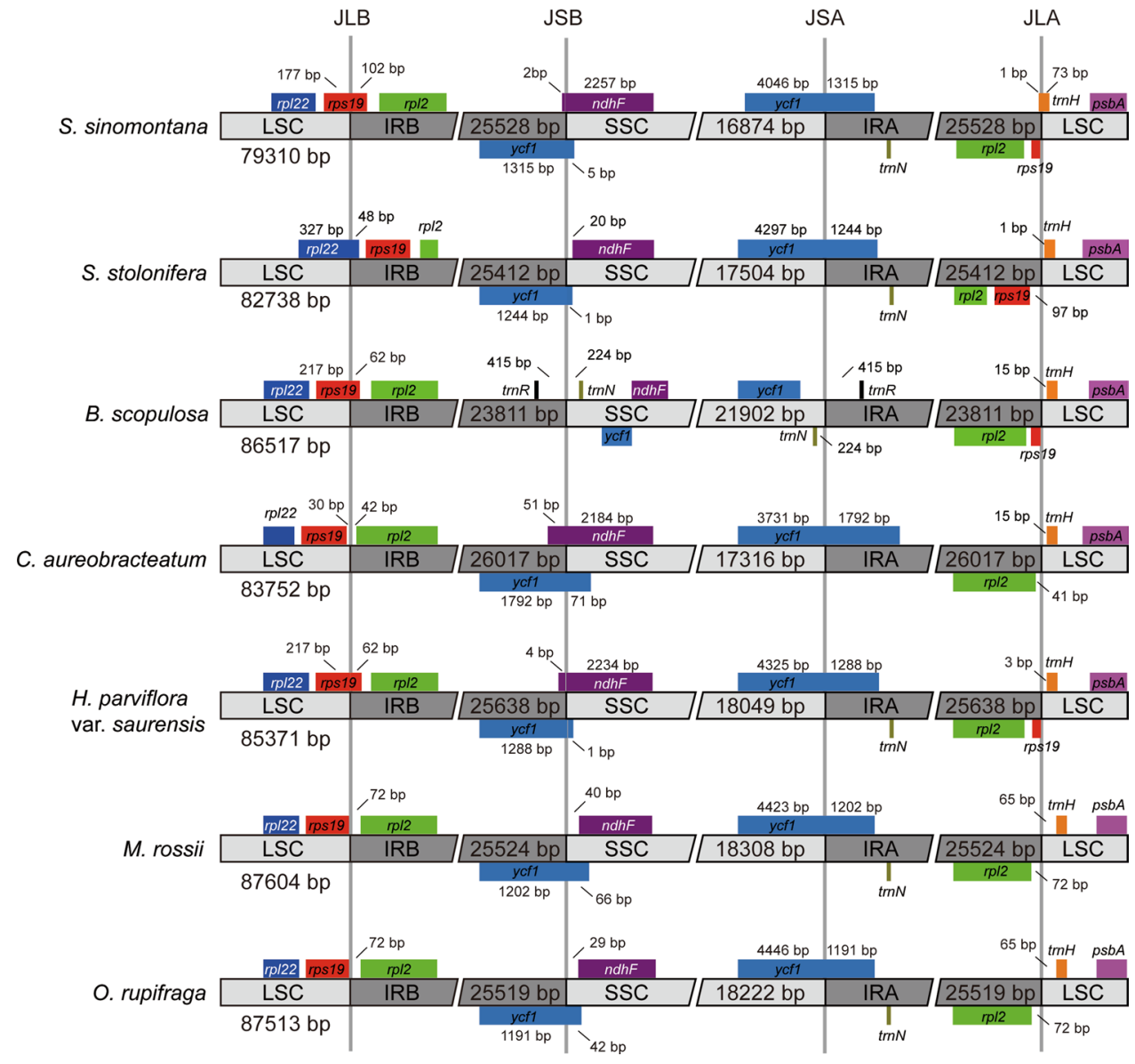

Table 3 Length and GC-content of the complete plastome, LSC, SSC and IR regions in seven Saxifragaceae species

\begin{tabular}{|c|c|c|c|c|c|c|c|c|}
\hline \multirow[t]{2}{*}{ Species } & \multicolumn{2}{|c|}{ Complete genome } & \multicolumn{2}{|l|}{ LSC } & \multicolumn{2}{|l|}{$\mathrm{SSC}$} & \multicolumn{2}{|l|}{ IR } \\
\hline & Length (bp) & $\mathrm{GC}(\%)$ & Length (bp) & $\mathrm{GC}(\%)$ & Length (bp) & $\mathrm{GC}(\%)$ & Length (bp) & $\mathrm{GC}(\%)$ \\
\hline S. sinomontana & 147,240 & 38.0 & 79,310 & 36.2 & 16,874 & 32.0 & 25,528 & 42.9 \\
\hline S. stolonifera & 151,066 & 37.8 & 82,738 & 35.9 & 17,504 & 32.2 & 25,412 & 43.0 \\
\hline B. scopulosa & 156,041 & 37.8 & 86,517 & 35.8 & 21,902 & 33.0 & 23,811 & 43.5 \\
\hline C. aureobracteatum & 153,102 & 37.3 & 83,752 & 35.2 & 17,316 & 31.1 & 26,017 & 42.8 \\
\hline H. parviflora var. saurensis & 154,696 & 37.8 & 85,371 & 35.9 & 18,049 & 32.2 & 25,638 & 43.1 \\
\hline M. rossii & 156,960 & 37.7 & 87,604 & 35.7 & 18,308 & 32.0 & 25,524 & 43.2 \\
\hline O. rupifraga & 156,773 & 37.7 & 87,513 & 35.7 & 18,222 & 32.2 & 25,519 & 43.2 \\
\hline
\end{tabular}

the genus Saxifraga (Zhang et al. 2008; Tkach et al. 2015; Gao et al. 2015). However, infrasectional relationships of the most species-rich section Ciliatae are still not well resolved (Zhang et al. 2008; Tkach et al. 2015; Gao et al. 2015), mostly due to the lack of resolutions within the recent divergent lineage of Saxifraga sect. Ciliatae subsect. Hirculoideae, in which informatively polymorphic sites are revealed to be limited (Gao et al. 2015). Chloroplast genomes comprise abundant phylogenetic information, which could have the potential to significantly advance our ability to resolve phylogenetic relationships in this lineage. The result of phylogenetic analysis revealed that seven Saxifragaceae species based on 66 protein-coding genes received high bootstrap support values for nearly all identified nodes, suggesting a promising opportunity to resolve infrasectional relationships of the most speciesrich section Ciliatae. This is the first chloroplast genome sequenced in $S$. sect. Ciliatae and also the second in the genus Saxifraga. More taxa, especially those of $S$. sect. Ciliatae subsect. Hirculoideae should be included in the chloroplast genome comparative analysis to realize the full 


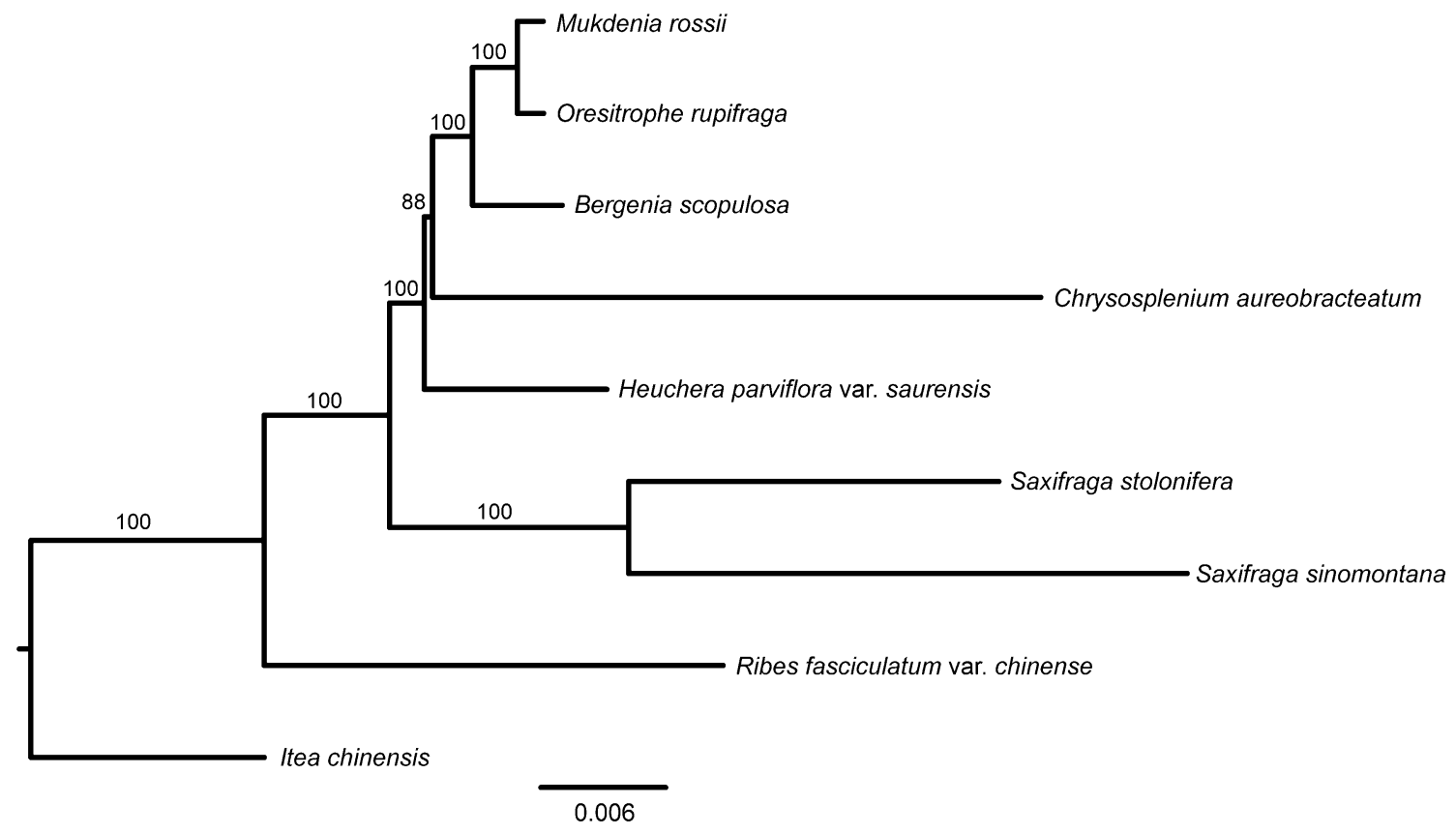

Fig. 4 The maximum-likelihood phylogenetic tree of seven Saxifragaceae species using 66 protein-coding genes of chloroplast genomes. Numbers above nodes are bootstrap support values

potential of chloroplast genomes in phylogenetic analysis of $S$. sect. Ciliatae.

Acknowledgements This study was supported by CAS Light of West China Program, Youth Innovation Promotion Association, CAS (Grant No. 2016378), Open Project of Qinghai Provincial Key Laboratory of Crop Molecular Breeding (Grant No. 2017-ZJY14), Application Fundamental Research Project of Qinghai Province (2019-ZJ-7019), High-end Innovative Talents Thousands of People Plan.

Author contributions Conceptualization: Qingbo Gao; Data Curation: Yan Li, Liukun Jia and Zhihua Wang; Formal Analysis: Rui Xing and Xiaofeng Chi; Resources: Shilong Chen; Writing-Original Draft Preparation: Yan Li; Writing — Review and Editing: Qingbo Gao; Funding Acquisition: Qingbo Gao and Shilong Chen.

\section{Compliance with ethical standards}

Conflict of interest The authors declare no conflicts of interest.

Open Access This article is distributed under the terms of the Creative Commons Attribution 4.0 International License (http://creativeco mmons.org/licenses/by/4.0/), which permits unrestricted use, distribution, and reproduction in any medium, provided you give appropriate credit to the original author(s) and the source, provide a link to the Creative Commons license, and indicate if changes were made.

\section{References}

Amiryousefi A, Hyvönen J, Poczai P (2018) IRscope: an online program to visualize the junction sites of chloroplast genomes. Bioinformatics 34:3030-3031
Bankevich A, Nurk S, Antipov D, Gurevich AA, Dvorkin M, Kulikov AS, Lesin VM, Nikolenko SI, Pham S, Prjibelski AD et al (2012) SPAdes: a new genome assembly algorithm and its application to single-cell sequencing. J Comput Biol 19:455-477

Boetzer M, Henkel CV, Jansen HJ, Butler D, Pirovano W (2011) Scaffolding pre-assembled contigs using SSPACE. Bioinformatics 27:578-579

Brudno M, Do CB, Cooper GM, Kim MF, Davydov E, NISC Comparative Sequencing Program, Green ED, Sidow A, Batzoglou S (2003) LAGAN and multi-LAGAN: efficient tools for large-scale multiple alignment of genomic DNA. Genome Res 13:721-731

Burke SV, Lin C-S, Wysocki WP, Clark LG, Duvall MR (2016) Phylogenomics and plastome evolution of tropical forest grasses (Leptaspis, Streptochaeta: Poaceae). Front Plant Sci 7:1993

Chi XF, Wang JL, Gao QB, Zhang FQ, Chen SL (2018) The complete chloroplast genomes of two Lancea species with comparative analysis. Molecules 23:602

Darriba D, Taboada GL, Doallo R, Posada D (2012) jModelTest 2: more models new heuristics and parallel computing. Nat Methods 9:772

DeChaine EG, Anderson SA, McNew JM, Wendling BM (2013) On the evolutionary and biogeographic history of Saxifraga sect. Trachyphyllum (Gaud.) Koch (Saxifragaceae Juss.). PLoS ONE 8:e69814

Deng JB, Drew BT, Mavrodiev EV, Gitzendanner MA, Soltis PS, Soltis DE (2015) Phylogeny divergence times and historical biogeography of the angiosperm family Saxifragaceae. Mol Phylogenet Evol 83:86-98

Dong WP, Xu C, Li CH, Sun JH, Zuo YJ, Shi S, Cheng T, Guo JJ, Zhou SL (2015) $y c f 1$ the most promising plastid DNA barcode of land plants. Sci Rep 5:8348

Dong WP, Xu C, Wu P, Cheng T, Yu J, Zhou SL (2018) Resolving the systematic positions of enigmatic taxa: manipulating the chloroplast genome data of Saxifragales. Mol Phylogenet Evol 126:321-330

Doorduin L, Gravendeel B, Lammers Y, Ariyurek Y, Chin-A-Woeng T, Vrieling K (2011) The complete chloroplast genome of 17 
individuals of pest species Jacobaea vulgaris: SNPs microsatellites and barcoding markers for population and phylogenetic studies. DNA Res 18:93-105

Doyle JJ, Doyle JL (1987) A rapid DNA isolation procedure for small quantities of fresh leaf tissue. Phytochem Bull Bot Soc Am 19:11-15

Doyle JJ, Davis JI, Soreng RJ, Garvin D, Anderson MJ (1992) Chloroplast DNA inversions and the origin of the grass family (Poaceae). Proc Natl Acad Sci USA 89:7722-7726

Doyle JJ, Doyle JL, Ballenger JA, Palmer JD (1996) The distribution and phylogenetic significance of a 50-kb chloroplast DNA inversion in the flowering plant family Leguminosae. Mol Phylogenet Evol 5:429-438

Ebersbach J, Muellner-Riehl AN, Michalak I, Tkach N, Hoffmann MH, Röser M, Sun H, Favre A (2017a) In and out of the Qinghai-Tibet Plateau: divergence time estimation and historical biogeography of the large arctic-alpine genus Saxifraga L. J Biogeogr 44:900-910

Ebersbach J, Schnitzler J, Favre A, Muellner-Riehl AN (2017b) Evolutionary radiations in the species-rich mountain genus Saxifraga $\mathrm{L}$. BMC Evol Biol 17:119

Ebersbach J, Muellner-Riehl AN, Favre A, Paule J, Winterfeld G, Schnitzler J (2018) Driving forces behind evolutionary radiations: Saxifraga section Ciliatae (Saxifragaceae) in the region of the Qinghai-Tibet Plateau. Bot J Linn Soc 186:304-320

Flannery ML, Mitchell FJG, Coyne S, Kavanagh TA, Burke JI, Salamin N, Dowding P, Hodkinson TR (2006) Plastid genome characterisation in Brassica and Brassicaceae using a new set of nine SSRs. Theor Appl Genet 113:1221-1231

Frazer KA, Pachter L, Poliakov A, Rubin EM, Dubchak I (2004) VISTA: computational tools for comparative genomics. Nucleic Acids Res 32:W273-W279

Fu PC, Zhang YZ, Geng HM, Chen SL (2016) The complete chloroplast genome sequence of Gentiana lawrencei var. farreri (Gentianaceae) and comparative analysis with its congeneric species. PeerJ 4:e2540

Gao QB, Li YH, Gornall RJ, Zhang ZX, Zhang FQ, Xing R, Fu PC, Wang JL, Liu HR, Tian ZZ et al (2015) Phylogeny and speciation in Saxifraga sect. Ciliatae (Saxifragaceae): evidence from psbA-trnH, trnL-F and ITS sequences. Taxon 64:703-713

Gao QB, Li Y, Gengji ZM, Gornall RJ, Wang JL, Liu HR, Jia LK, Chen SL (2017) Population genetic differentiation and taxonomy of three closely related species of Saxifraga (Saxifragaceae) from Southern Tibet and the Hengduan Mountains. Front Plant Sci 8:1325

Greiner S, Lehwark P, Bock R (2019) OrganellarGenomeDRAW (OGDRAW) version 1.3.1: expanded toolkit for the graphical visualization of organellar genomes. Nucleic Acids Res 47:W59-W64

Hernández-León S, Gernandt DS, Pérez de la Rosa JA, Jardón-Barbolla L (2013) Phylogenetic relationships and species delimitation in Pinus section Trifoliae inferred from plastid DNA. PLoS ONE 8:e70501

Hu S, Sablok G, Wang B, Dong Q, Barbaro E, Viola R, Li M, Varotto C (2015) Plastome organization and evolution of chloroplast genes in Cardamine species adapted to contrasting habitats. BMC Genom 16:306

Huang H, Shi C, Liu Y, Mao SY, Gao LZ (2014) Thirteen Camellia chloroplast genome sequences determined by high-throughput sequencing: genome structure and phylogenetic relationships. BMC Evol Biol 14:151

Ivanova Z, Sablok G, Daskalova E, Zahmanova G, Apostolova E, Yahubyan G, Baev V (2017) Chloroplast genome analysis of resurrection tertiary relict Haberlea rhodopensis highlights genes important for desiccation stress response. Front Plant Sci 8:204
Jansen RK, Palmer JD (1987) A chloroplast DNA inversion marks an ancient evolutionary split in the sunflower family (Asteraceae). Proc Natl Acad Sci USA 84:5818-5822

Jansen RK, Cai Z, Raubeson LA, Daniel H, dePamphilis CW, LeebensMack J, Müller KF, Guisinger-Bellian M, Haberle RC, Hansen AK et al (2007) Analysis of 81 genes from 64 plastid genomes resolves relationships in angiosperms and identifies genome-scale evolutionary patterns. Proc Natl Acad Sci USA 104:19369-19374

Kim KJ, Jansen RK (1995) $n d h F$ sequence evolution and the major clades in the sunflower family. Proc Natl Acad Sci USA 92:10379-10383

Kuang DY, Wu H, Wang YL, Gao LM, Zhang SZ, Lu L (2011) Complete chloroplast genome sequence of Magnolia kwangsiensis (Magnoliaceae): implication for DNA barcoding and population genetics. Genome 54:663-673

Kumar S, Stecher G, Tamura K (2016) MEGA7: molecular evolutionary genetics analysis version 7.0 for bigger datasets. Mol Biol Evol 33:1870-1874

Li H, Durbin R (2009) Fast and accurate short read alignment with Burrows-Wheeler transform. Bioinformatics 25:1754-1760

Li Y, Gao QB, Gengji ZM, Jia LK, Wang ZH, Chen SL (2018) Rapid intraspecific diversification of the alpine species Saxifraga sinomontana (Saxifragaceae) in the Qinghai-Tibetan Plateau and Himalayas. Front Genet 9:381

Li W, Zhang CP, Guo X, Liu QH, Wang KL (2019) Complete chloroplast genome of Camellia japonica genome structures comparative and phylogenetic analysis. PLoS ONE 14:e0216645

Liu Y, Huo N, Dong L, Wang Y, Zhang S, Young HA, Feng X, Gu YQ (2013) Complete chloroplast genome sequences of Mongolia medicine Artemisia frigida and phylogenetic relationships with other plants. PLoS ONE 8:e57533

Ni LH, Zhao ZL, Xu HX, Chen SL, Dorje G (2016) The complete chloroplast genome of Gentiana straminea (Gentianaceae) an endemic species to the Sino-Himalayan subregion. Gene 577:281-288

Nie XJ, Lv SZ, Zhang YX, Du XH, Wang L, Biradar SS, Tan XF, Wan FH, Weining S (2012) Complete chloroplast genome sequence of a major invasive species crofton weed (Ageratina adenophora). PLoS ONE 7:e36869

Palmer JD (1985) Comparative organization of chloroplast genomes. Annu Rev Genet 19:325-354

Pan JT, Gornall RJ, Ohba H (2001) Saxifraga. In: Wu CY, Raven PH (eds) Flora of China. Science Press, Beijing; Missouri Botanical Garden Press, St Louis, pp 280-334

Powell W, Morgante M, McDevitt R, Vendramin GG, Rafalski JA (1995) Polymorphic simple sequence repeat regions in chloroplast genomes: applications to the population genetics of pines. Proc Natl Acad Sci USA 92:7759-7763

Provan J, Russell JR, Booth A, Powell W (1999) Polymorphic chloroplast simple sequence repeat primers for systematic and population studies in the genus Hordeum. Mol Ecol 8:505-511

Provan J, Powell W, Hollingsworth PM (2001) Chloroplast microsatellites: new tools for studies in plant ecology and evolution. Trends Ecol Evol 16:142-147

Silvestros D, Michalak I (2012) raxmlGUI: a graphical front-end for RAxML. Org Divers Evol 12:335-337

Simmons MP (2017) Mutually exclusive phylogenomic inferences at the root of the angiosperms: Amborella is supported as sister and observed variability is biased. Cladistics 33:488-512

Soltis DE, Kuzoff RK, Mort ME, Zanis M, Fishbein M, Hufford L, Koontz J, Arroyo MK (2001) Elucidating deep-level phylogenetic relationships in Saxifragaceae using sequences for six chloroplastic and nuclear DNA regions. Ann Mo Bot Gard 88:669-693

Soltis DE, Mort ME, Latvis M, Mavrodiev EV, O'Meara BC, Soltis PS, Burleigh JG, Rubio de Casas R (2013) Phylogenetic relationships and character evolution analysis of Saxifragales using a supermatrix approach. Am J Bot 100:916-929 
Stamatakis A (2014) RAxML version 8: a tool for phylogenetic analysis and post-analysis of large phylogenies. Bioinformatics 30:1312-1313

Sun SS, Fu PC, Zhou XJ, Cheng YW, Zhang FQ, Chen SL, Gao QB (2018) The complete plastome sequences of seven species in Gentiana sect. Kudoa (Gentianaceae): insights into plastid gene loss and molecular evolution. Front Plant Sci 9:493

Thiel T, Michalek W, Varshney RK, Graner A (2003) Exploiting EST databases for the development and characterization of genederived SSR-markers in barley (Hordeum vulgare L). Theor Appl Genet 106:411-422

Tillich M, Lehwark P, Pellizzer T, Ulbricht-Jones ES, Fischer A, Bock $\mathrm{R}$, Greiner S (2017) GeSeq-versatile and accurate annotation of organelle genomes. Nucleic Acids Res 45:W6-W11

Tkach N, Röser M, Miehe G, Muellner-Riehl AN, Ebersbach J, Favre A, Hoffmann MH (2015) Molecular phylogenetics morphology and a revised classification of the complex genus Saxifraga (Saxifragaceae). Taxon 64:1159-1187

Walker JF, Zanis MJ, Emery NC (2014) Comparative analysis of complete chloroplast genome sequence and inversion variation in Lasthenia burkei (Madieae Asteraceae). Am J Bot 101:722-729

Wang RJ, Cheng CL, Chang CC, Wu CL, Su TM, Chaw SM (2008) Dynamics and evolution of the inverted repeat-large single copy junctions in the chloroplast genomes of monocots. BMC Evol Biol 8:36

Wang WB, Yu H, Wang JH, Lei WJ, Gao JH, Qiu XP, Wang JS (2017) The complete chloroplast genome sequences of the medicinal plant Forsythia suspensa (Oleaceae). Int J Mol Sci 18:2288

Wicke S, Schneeweiss GM, dePamphilis CW, Müller KF, Quandt D (2011) The evolution of the plastid chromosome in land plants: gene content gene order gene function. Plant Mol Biol 76:273-297
Xiang CL, Gitzendanner MA, Soltis DE, Peng H, Lei LG (2012) Phylogenetic placement of the enigmatic and critically endangered genus Saniculiphyllum (Saxifragaceae) inferred from combined analysis of plastid and nuclear DNA sequences. Mol Phylogenet Evol 64:357-367

Xue J, Wang S, Zhou SL (2012) Polymorphic chloroplast microsatellite loci in Nelumbo (Nelumbonaceae). Am J Bot 99:e240-e244

Yan C, Du JC, Gao L, Li Y, Hou XL (2019) The complete chloroplast genome sequence of watercress (Nasturtium officinale $\mathrm{R} \mathrm{Br}$ ): genome organization adaptive evolution and phylogenetic relationships in Cardamineae. Gene 699:24-36

Yang J, Vázquez L, Chen XD, Li HM, Zhang H, Liu ZL, Zhao GF (2017) Development of chloroplast and nuclear DNA markers for Chinese oaks (Quercus subgenus Quercus) and assessment of their utility as DNA barcodes. Front Plant Sci 8:816

Ye J, Coulouris G, Zaretskaya I, Cutcutache I, Rozen S, Madden TL (2012) Primer-BLAST: a tool to design target-specific primers for polymerase chain reaction. BMC Bioinformatics 13:134

Zhang DJ, Chen SY, Gao QB, Duan YZ, Chen SL (2008) Circumscription and phylogeny of Saxifraga sect. Ciliatae: evidence from nrDNA ITS sequences. J Syst Evol 46:667-675

Zhu WD, Nie ZL, Wen J, Sun H (2013) Molecular phylogeny and biogeography of Astilbe (Saxifragaceae) in Asia and eastern North America. Bot J Linn Soc 171:377-394

Publisher's Note Springer Nature remains neutral with regard to jurisdictional claims in published maps and institutional affiliations. 